\title{
1 A bio-optical model for integration into ecosystem models for the Ligurian
}

2 Sea

3

4 Fethi Bengil ${ }^{1 *}$, David $\mathrm{McKee}^{2}$, Sükrü T. Beşiktepe ${ }^{3}$, Violeta Sanjuan Calzado ${ }^{4}$, and Charles 5 Trees $^{4}$.

$6{ }^{1}$ Marine School - Earth System Science Research Centre. Girne American University, 7 University Drive, Girne, TRNC via Mersin 10 Turkey

$8 \quad 2$ Physics Department, University of Strathclyde, 107 Rottenrow, Glasgow, G4 0NG, Scotland

$9{ }^{3}$ Institute of Marine Sciences and Technology, Dokuz Eylül University, Bakü Bulv. No:100, 1035100 , İnciraltt, İzmir Turkey

$11{ }^{4}$ Centre for Maritime Research and Experimentation, 400 Viale San Bartolomeo, 19126La 12 Spezia (SP), Italy

13 Corresponding author. E-mail address: fethibengil@gau.edu.tr.

14

15 Keywords: Bio-optical model, Ligurian Sea, ocean colour, photosynthetically available 16 radiation

18 Abstract:

19 A bio-optical model has been developed for the Ligurian Sea which encompasses both deep, 20 oceanic Case 1 waters and shallow, coastal Case 2 waters. The model builds on earlier Case 1 21 models for the region and uses field data collected on the BP09 research cruise to establish new 22 relationships for non-biogenic particles and CDOM. The bio-optical model reproduces in situ 23 IOPs accurately and is used to parameterize radiative transfer simulations which demonstrate 24 its utility for modeling underwater light levels and above surface remote sensing reflectance. 25 Prediction of euphotic depth is found to be accurate to within $\sim 3.2 \mathrm{~m}$ (RMSE). Previously 
26 published light field models work well for deep oceanic parts of the Ligurian Sea that fit the

27 Case 1 classification. However, they are found to significantly over-estimate euphotic depth in optically complex coastal waters where the influence of non-biogenic materials is strongest. For these coastal waters, the combination of the bio-optical model proposed here and full radiative transfer simulations provides significantly more accurate predictions of euphotic depth.

\section{Introduction}

The temporal and spatial variability of oceanic optical properties are fundamental to many biogeochemical processes in the sea (Dickey and Falkowski 2002). Underwater light fields regulate photosynthesis, contribute to solar heating and determine remotely sensed ocean colour signals. In recent years it has become increasingly apparent that coupled physicalecosystem models require appropriate representation of the underwater light field, particularly in the context of using ocean colour remote sensing data for assimilation and validation (Rothstein et al. 2006, Dickey et al. 2006, Fujii et al. 2007). Advances in computing power and availability of fast and accurate radiative transfer models (e.g. Ecolight, Sequoia Scientific) offer the potential to incorporate comprehensive light field models into aquatic ecosystem models, with the promise of significant improvements in the prediction of biogeochemical and physical properties (Mobley et al. 2015).

Early attempts to integrate light field models into coupled ecosystem models tended to use very basic approaches to modeling the underwater light field. For example, Beşiktepe et al. (2003) used chlorophyll concentration $(C h l)$ and the Lambert-Beer law to obtain attenuation coefficients and from this estimated underwater light fields. Penta et al. (2008 and 2009) adapted the innovative method of Lee et al. (2005) to obtain underwater light attenuation for 
51 model underwater light fields (e.g. Fujii et al. 2007, Shulman et al. 2013, Ciavatta et al. 2014).

52 Future efforts, incorporating full solution of the radiative transfer equation, will require parameterization with a complete set of inherent optical properties, IOPs (Trees et al. 2009). Moreover, there will be a need to relate these IOPs to relevant ecosystem model currencies in order to track evolution of the light field in time and space with changes in physical and biogeochemical properties of the system. Considerable effort has already gone into the development of bio-optical models for different natural water systems (Prieur and Sathyendranath 1981, Gordon and Morel 1981, Morel 1988, Bricaud et al. 1995, Bricaud et al. 1998, Loisel and Morel 1998, Morel and Maritorena 2001, Velluci 2007, and Morel 2009). Most bio-optical models are constructed using optically significant constituents (OSC) as currency terms, with typical components such as: phytoplankton, detrital or non-algal particles and coloured dissolved organic material (CDOM). Even such a simple scheme presents difficulties in terms of relating optical variables to parameters that can be included in an ecosystem model currency scheme. Phytoplankton is the least awkward component, usually being represented by chlorophyll concentration as a proxy currency. The remainder of the particle population is much harder to define. In oceanic systems, operating under the Case 1 definition, other particles may be assumed to be derived from the phytoplankton population, e.g. detrital particles and associated bacterial populations, and these might also be related to Chl. However, in shallow coastal waters there is also the potential for significant populations of non-biogenic particles from terrigenous sources or from benthic resuspension. These 71 particles are unlikely to be related to $C h l$ and must, instead, be represented by some measure 72 of total suspended solid concentration (TSS). However, given the contribution from 73 phytoplankton and associated biogenic materials to TSS, there is an a priori requirement for 74 consideration of further refinement of this parameterization to account for the complex nature 75 of the particle population. CDOM is also problematic when considering Case 1 versus Case 2 
scenarios. Under the Case 1 approach, $C D O M$ is assumed to be a product of algal-related biological activity and has been successfully related to $C h l$ for oceanic waters (Prieur \& Sathyendranath 1981, Bricaud et al. 1998). However, coastal areas subject to riverine inputs will present $C D O M$ signals that are unrelated to $C h l$. Here there are grounds for investigating the potential of relating $C D O M$ signals to salinity given the association with freshwater inputs (e.g. Bowers et al. 2008 and references therein).

The study area for this paper is the Ligurian Sea, which is located in the northwestern part of the Mediterranean Sea between southeast France, northwest Italy and the island of Corsica (Figure 1). This is an area which has been extensively studied previously with wellestablished circulation patterns, e.g. Astraldi \& Gasparini (1992). Cyclonic circulation in the Ligurian Sea leads to the formation of three distinct hydrological zones; a thermal front (frontal zone) which separates less dense warm coastal peripheral water (coastal zone) from denser cold offshore water (central zone) (Picco et al. 2010 and references therein). These structures are permanent but show some seasonal and interannual variability (Astraldi et al. 1990, Picco et al. 2010). The upper layer of the Ligurian Sea has seasonal differences in nutrient ratios with changes from nitrate limitation in winter to phosphate limitation in summer due to seasonal hydrological regime variations (Marty et al. 2002). Nutrient availability is controlled by vertical mixing and determines the timing of algal blooms. Winter mixing leads to the formation of a winter - early spring bloom while a second bloom in April - May depends on subsequent mixing events (Raick et al. 2005).

The aim of this study is to develop and test a bio-optical model for the Ligurian Sea, which uses Chl, TSS and Salinity as the currency exchange with an ecosystem model, based upon derivation of appropriate mass-specific inherent optical properties with different versions for deep offshore waters and shallow, optically complex coastal waters. This is an important step for establishing a conceptual framework to integrate a robust bio-optical model into future 
101 coupled physical-ecosystem models for this region. The choice of OSC currency parameters

102 (Chl, TSS and Salinity) reflects parameters that could be obtained both from autonomous in situ

103 sensor systems and from ecosystem model outputs. Chl and TSS may also be derived from

104 ocean colour remote sensing, whilst salinity can be obtained from microwave remote sensing 105 e.g. Aquarius and SMOS (Klemas 2011).

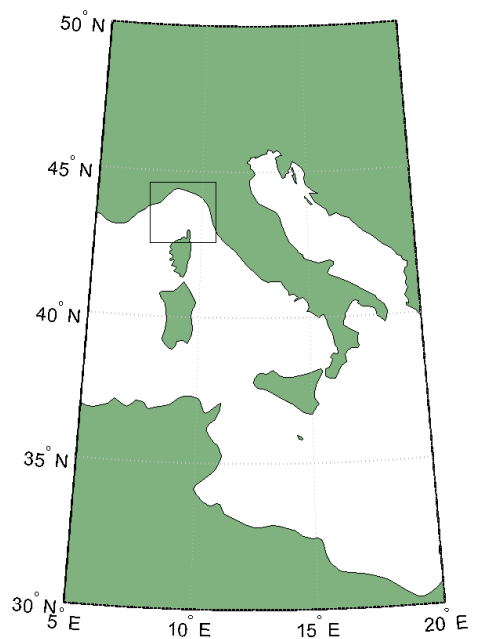

(a)

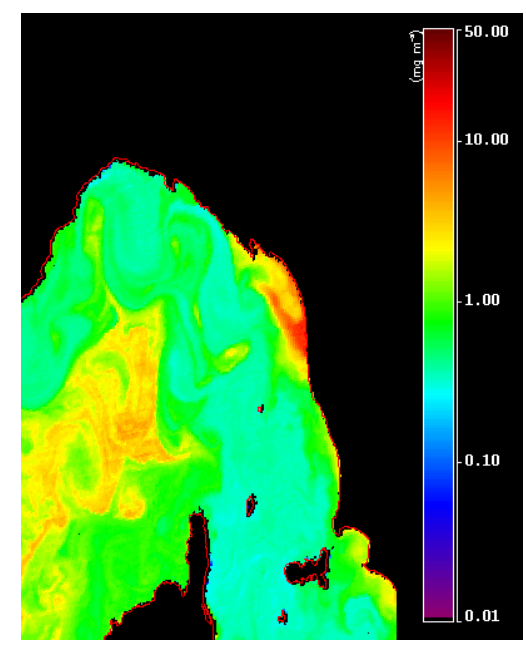

(c)

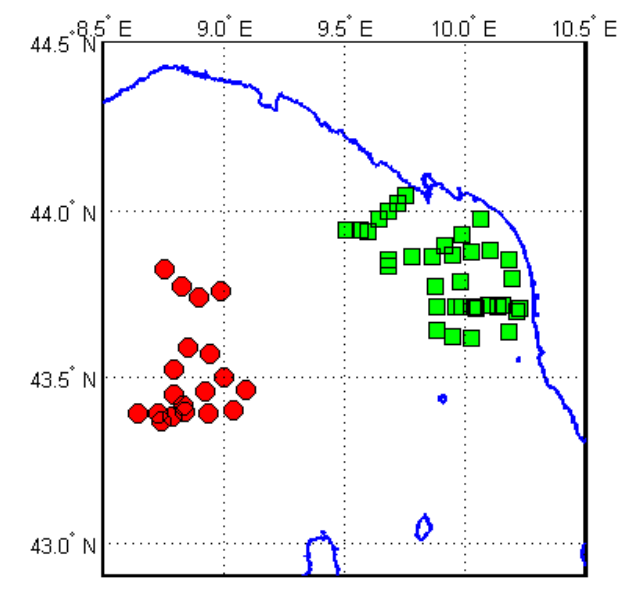

(b)

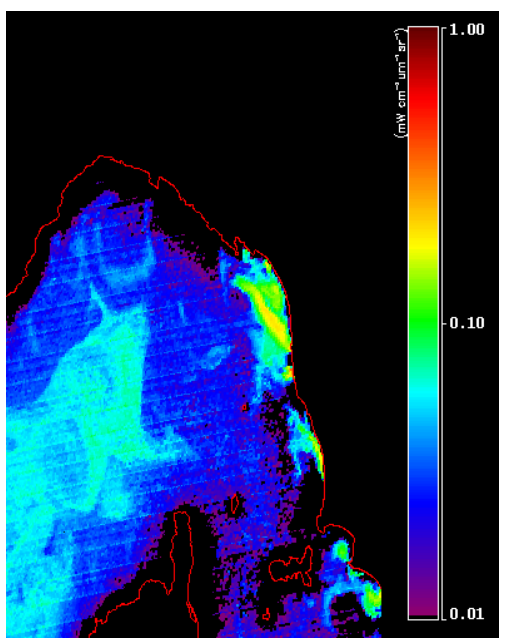

(d)
106

107

108

109

110

111

112

113

Figure 1. (a) Study area and (b) location of offshore (circles) and onshore (squares) stations for the BP09 cruise. (c) MODIS standard Chl from $18^{\text {th }}$ March 2009 shows a bloom in the central region of the Ligurian Sea, northwest of Corsica. The high intensity "bloom" on the Italian coast is actually a sediment plume from the River Arno, which is clearly identified from (d) MODIS $n L w 667$ from the same date. 
The data used in this study were collected during the BP09 Cruise between March $13^{\text {th }}$ and $26^{\text {th }} 2009$ in the Ligurian Sea on board NR/V Alliance. Figure 1 shows the locations of the sampling stations. Stations can be classified into two groups; onshore and offshore. The onshore group includes stations located on the coastal shelf and along transects perpendicular to the coast. A number of these stations were impacted significantly by terrigenous materials from the River Arno plume. The offshore group includes stations located in the Ligurian-

122 Provencal Basin and represent deep, clear oceanic waters that are separated from the coastal 123 zone by a permanent thermal front.

Hydrographic measurements were made using a Seabird SBE 9 CTD system equipped with temperature, conductivity, fluorescence and turbidity sensors. Fluorescence data were calibrated using chlorophyll- $a$ concentrations from HPLC measurements, while turbidity data were calibrated using total suspended solids measurements. These were used to generate proxy profiles of $C h l$ and TSS subsequently used in modelling efforts. samples filtered through GF/F filters, stored in liquid nitrogen and transported to laboratories

131 for later analysis. Chl data presented here were collected by colleagues from Management Unit 132 of the North Sea Mathematical Models (MUMM). Triplicate HPLC samples were analyzed by 133 the Marine Chemistry Laboratory of the MUMM using a reversed phase, acetone-based method 134 with a C18 column and a Jasco FP-1520 fluorescence detector. In this paper Chl refers to the chlorophyll $a$ concentration and does not include contributions from other pigments.

137 by filtering samples through pre-ashed, rinsed and pre-weighed $47 \mathrm{~mm} \mathrm{GF/F}$ filters. Samples 138 were rinsed with several aliquots of ultrapure water, taking care to rinse the edge of the filter 
to minimize salt retention. Filters were stored frozen and returned to the lab where they were 140 dried and reweighed.

141 The absorption of all dissolved and suspended components minus water was measured 142 using a Point Source Integrating Cavity Absorption Meter (PSICAM) (Röttgers et al. 2005, 143 2007; Röttgers \& Doerffer 2007). This instrument has previously been extensively validated 144 and has been shown to provide high accuracy ( $\pm 2 \%)$ absorption coefficients across a wide range of water conditions. A 1 m liquid waveguide capillary cell (LWCC) with an Ocean Optics

146 USB2000 mini-spectrometer was used to measure absorption by CDOM. This instrument is 147 somewhat faster to operate than the PSICAM and provides noise range of $\pm 0.0001 \mathrm{~m}^{-1}(95 \%$ 148 Prediction Interval) at $532 \mathrm{~nm}$. In both cases, measurements were made against fresh Milli-Q 149 references and all samples were corrected for the effects of salinity and temperature on water 150 absorption (Röttgers \& Doerffer 2007). From this pair of measurements particulate absorption, $a_{p}(\lambda)$, was derived by subtraction of CDOM absorption, $a_{C D O M}$, from PSICAM non-water 152 absorption, $a_{P S I C A M}$.

153 Particulate optical density $\left(O D_{p}\right)$ was measured on freshly filtered samples using a 154 Shimadzu UV-2501 PC dual beam spectrophotometer. Between 1 and 2 litres of sample were 155 filtered through a $25 \mathrm{~mm} \mathrm{GF/F} \mathrm{filter} \mathrm{with} \mathrm{nominal} 0.7 \mu \mathrm{m}$ retention limit which was mounted 156 directly against the exit port of the spectrophotometer sample chamber. An unused GF/F filter, 157 wetted with $0.2 \mu \mathrm{m}$ filtered seawater from the same station, was used as a reference sample 158 and mounted on the reference port of the spectrophotometer. After measuring particulate 159 optical density, the sample filter was exposed to a dilute sodium hypochlorite solution until 160 visual loss of pigmentation occurred. The bleached filter pad was rinsed with $0.2 \mu \mathrm{m}$ filtered 161 seawater before being returned to the sample detector and a further scan for detrital optical 162 density $\left(O D_{d e t}\right)$ was completed. Detrital absorption spectra were visually examined to ensure 
163 that all pigment features, including phycobiliproteins, were removed. The sample was re-

164 bleached and re-scanned if necessary. The absorption coefficient is obtained from

165

$$
a_{p}(\lambda)=2.303 \frac{A_{f p} O D_{p}(\lambda)}{V_{v} \beta}
$$

166 where $A_{f p}$ is the exposed area of the filter pad, $V_{f}$ is the volume of sample filtered and $\beta$ is the 167 pathlength amplification factor. Filter pad absorption spectra were initially baseline corrected at $750 \mathrm{~nm}$ (Cleveland and Weidemann 1993). Equation (1) can be rewritten for detrital absorption $a_{d e t}$ by replacing $O D_{p}$ with $O D_{\text {det }}$. Samples were corrected for pathlength amplification using a novel procedure described in detail in McKee et al. (2014). This approach uses linear regression of filter pad absorption against particulate absorption obtained by subtracting CDOM absorption from total non-water absorption measured by the PSICAM to provide both the pathlength amplification factor and offset correction for each sample. These values were then also used to correct bleached filter pad absorption measurements giving $a_{d e t}$, with phytoplankton absorption coefficients, $a_{p h}$, finally obtained by subtracting detrital absorption from total particulate absorption. and attenuation meter (WET Labs Inc.) with a $25 \mathrm{~cm}$ path-length operating at 412, 440, 510, 532, 555, 650, 676 and $715 \mathrm{~nm}$. AC-9 measurements were calibrated during the cruise with ultrapure water (Milli-Q, Millipore) and the salinity and temperature dependence of pure water were corrected in all samples (Pegau et al. 1997) using data from a Seabird SBE 19 plus CTD.

182 The proportional correction by Zaneveld et al. (1994) was used to correct AC-9 absorption data for scattering collection errors. In situ backscattering measurements were made with a BB9 backscattering meter (WET Labs Inc.) operating at 412, 440, 510, 532, 595, 660, 676, 715 nm. BB9 data were linearly interpolated where necessary to match AC-9 wavelengths and were corrected for temperature, salinity and path length absorption effects in line with the 187 manufacturer's instructions. The AC-9 and BB9 were deployed simultaneously, measuring 
188 IOPs from the surface to the maximum depth possible in shallow stations or down to a maximum of $100 \mathrm{~m}$ for deeper stations. configured with hyper-spectral radiometric sensors measuring downwelling irradiance $\left(E_{d}\right)$ and upwelling radiance $\left(L_{u}\right)$, with a reference above-surface irradiance $\left(E_{s}\right)$ sensor mounted at an 193 elevated point where the ship's superstructure had minimal effect. The profiling radiometer was deployed in a multicast mode to sample the surface layer repeatedly at each station enabling optimal calculation of light field parameters in the top $10 \mathrm{~m}$ (Zibordi et al. 2011). In addition, where possible, a deep radiometer cast was collected enabling observation of light

197 penetration below the surface layer. A data processing routine was developed to correct for 198 changes in solar elevation during the cast sequence and to minimize the impact of surface effects (based on Sanjuan Calzado et al. 2011). running with IOPs derived from the bio-optical model developed below and Fournier - Forand scattering phase functions generated from particulate backscattering ratio $\left(b_{b p}(\lambda) / b_{p}(\lambda)\right)$ following Mobley et al. (2002). Output wavelengths and depths were chosen to match AC-9 wavelengths and measured above surface downwards irradiance data were used to set boundary conditions. Raman scattering by water was included in simulations, but due to uncertainty in selection of appropriate quantum yield values, fluorescence contributions from CDOM and 207 phytoplankton were not included in simulations (see Lefering et al. 2016 for detailed 208 information).

MERIS above surface remote sensing reflectance data were processed using the Case 2

210 Region (C2R) algorithm module (Doerffer \& Schiller 2007), in Beam-VISAT software 211 (Brockmann Consult). In situ data were matched to the geographically closest image pixel for 212 cloud-free images with a maximum one-day shift, before or after. 


\subsection{Bio-optical model development}

The Ligurian Sea contains deep, open ocean waters that are broadly consistent with the

216 Case 1 classification where $O S C$ are associated with algal production. For these waters it is

217 relatively simple to establish a fairly standard Case 1 bio-optical model with the following 218 form:

219 Case 1 IOP model:

$$
\begin{gathered}
a(\lambda)=a_{w}(\lambda)+a_{p h}(\lambda)+_{b i o} a_{\text {nap }}(\lambda)+_{b i o} a_{c d o m}(\lambda) \\
b(\lambda)=b_{w}(\lambda)+_{b i o} b_{p}(\lambda) \\
b_{b}(\lambda)=b_{b w}(\lambda)+_{b i o} b_{b p}(\lambda)
\end{gathered}
$$

where $a(\lambda), b(\lambda)$, and $b_{b}(\lambda)$ are spectral absorption, scattering and backscattering coefficients.

Subscripts $w$, ph, nap and CDOM refer to water, phytoplankton, non-algal particles and

coloured dissolved organic material, while the subscript $p$ refers to particles. The subscript bio

226 has been introduced to emphasise that the Case 1 assumption implies that NAP absorption,

227 CDOM absorption and particulate scattering and backscattering are all assumed to be biogenic in origin and will subsequently be related to the phytoplankton $(C h l)$ concentration. Note that the biogenic scattering and backscattering components include all particles present in these waters i.e. phytoplankton and any other associated particles such as biogenic detritus.

232 freshwater inflows and resuspension of benthic materials in shallow waters. The following 233 Case 2 bio-optical model is intended to reflect the more complex OSC composition of these 234 waters.

\section{Case 2 IOP model:}

$$
a(\lambda)=a_{w}(\lambda)+a_{p h}(\lambda)+_{\text {bio }} a_{\text {nap }}(\lambda)+_{\text {nonbio }} a_{\text {nap }}(\lambda)+_{\text {bio }} a_{\text {CDOM }}(\lambda)+_{\text {nonbio }} a_{C D O M}(\lambda)
$$




$$
b(\lambda)=b_{w}(\lambda)+_{b i o} b_{p}(\lambda)+_{n o n b i o} b_{p}(\lambda)
$$

$$
b_{b}(\lambda)=b_{b w}(\lambda)+_{b i o} b_{b p}(\lambda)+_{n o n b i o} b_{b p}(\lambda)
$$

239 The Case 2 absorption model builds on the Case 1 version by adding nonbiogenic (nonbio) 240 NAP particles, effectively an independent sediment fraction, and non-biogenic CDOM absorption, which is intended to reflect freshwater sources of CDOM. Case 2 scattering and

242 backscattering models include additional non-biogenic components, again reflecting 243 contributions, e.g. sediment resuspension, that are independent of the phytoplankton 244 population. relevant ecosystem model currency parameter. For the Case 1 model, the relevant ecosystem model currency is $C h l$. There is a wealth of literature on potential Case 1 relationships from which the following were selected having been found to provide reasonable fits with the offshore section of the BP09 data and the global NOMAD data set (Werdell \& Bailey 2005). For example, Figure 2 shows the relationship between two wavelengths of phytoplankton absorption and $C h l$ and with corresponding modelled values from Bricaud et al. (1995) and a more recent parameterisation of the same model by Vellucci, (2007). In this case the Vellucci parameterisation was chosen and has the form

$$
a_{p h}(\lambda)=A(\lambda) C h l^{B(\lambda)}
$$

Absorption by what is assumed here to be biogenic non-algal particles follows Bricaud et al.

256 (1998) and is given by

$$
{ }_{\text {bio }} a_{\text {nap }}(440)=0.0124 C h l^{0.724}
$$

258 with the spectral dependence given by

$$
a_{\text {nap }}(\lambda)=_{\text {bio }} a_{\text {nap }}(440) \exp [-0.011(\lambda-440)]
$$

260 CDOM absorption for Case 1 waters is estimated from Prieur \& Sathyendranath (1981)

$$
{ }_{\text {bio }} a_{C D O M}(440)=0.2\left[a_{w}(440)+0.06 C h l^{0.65}\right]
$$


and the spectral dependency of CDOM absorption is given by Babin et al. (2003)

$$
a_{C D O M}(\lambda)=a_{C D O M}(440) \exp [-0.017(\lambda-440)]
$$

264 Particulate scattering and backscattering for Case 1 waters are derived from Velluci (2007)

$$
{ }_{b i o} b_{p}(\lambda)=0.22[C h l]^{0.612}(555 /(\lambda))
$$

266 and

$$
{ }_{b i o} b_{b p}(\lambda)=A(\lambda) C h l^{B(\lambda)}
$$

268 with $A(\lambda)$ and $B(\lambda)$ coefficients given in Table 5.8 in Velluci (2007). Regression coefficients 269 for modelled vs measured IOPs in Case 1 waters are provided in Table 1.

$$
T S S_{b i o}=0.285 C h l
$$

276 Eq.16 can be used to estimate the biogenic component of TSS in Case 2 waters, with the 277 nonbiogenic TSS obtained by subtraction:

$$
T S S_{\text {nonbio }}=T S S_{\text {Case } 2}-T S S_{\text {bio }}
$$



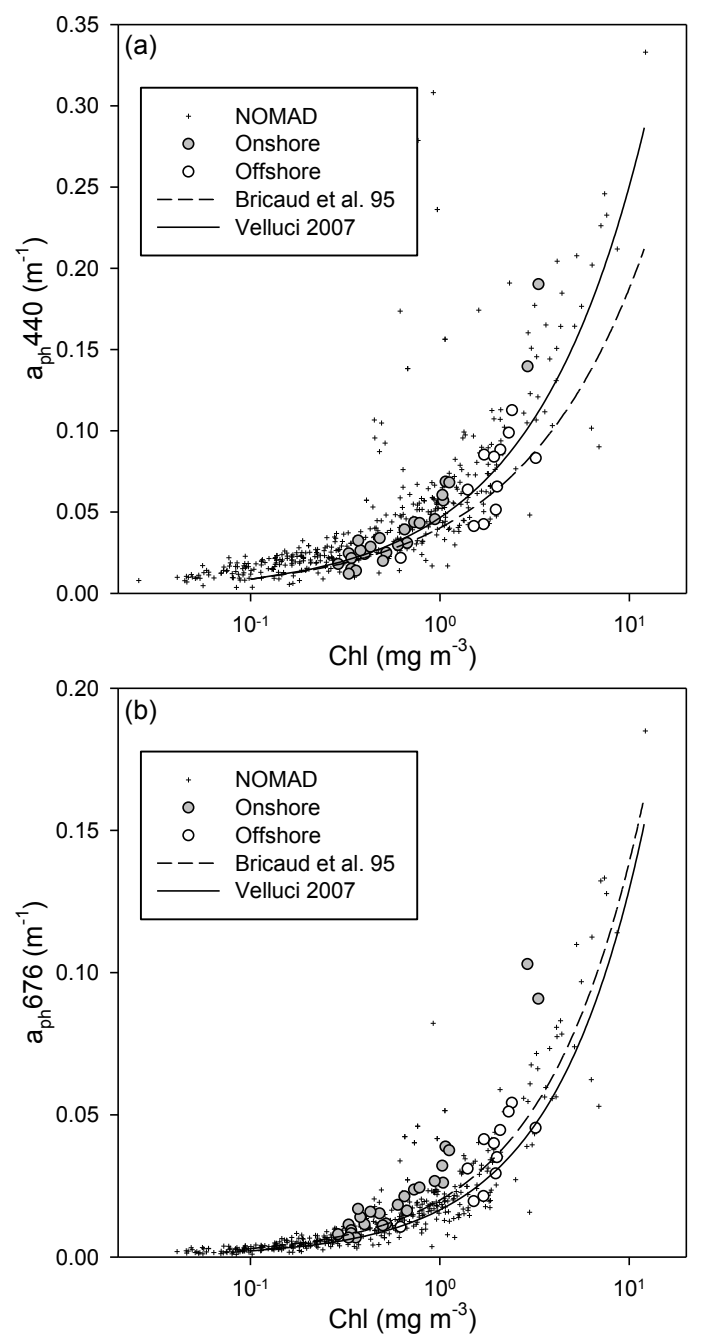

281 Figure 2. Relationship between $a_{p h}$ and $C h l$ at (a) $440 \mathrm{~nm}$ and (b) at $676 \mathrm{~nm}$ for the NOMAD 282 and Ligurian Sea data sets. The Vellucci (2007) parameterization of the Bricaud et al. (1995) 283 model provides an excellent fit to the NOMAD data set over the full spectral range.

285 Whilst it is possible to experimentally partition TSS into combustible and non-combustible 286 components, these do not necessarily provide helpful measures for this type of modelling as, 287 for example, the presence of diatom frustules in the non-combustible component potentially 288 breaches the biogenic vs. nonbiogenic partitioning. The TSS partitioning approach presented 289 here is admittedly a little crude, but has the merit of maintaining consistency with the overall 290 model development strategy. For Case 2 waters, the absorption by nonbiogenic particles is 
291 obtained by subtracting bio $a_{n a p}$ obtained using Eqs. 10 and 11 from measured $a_{d e t}$. Likewise, 292 nonbiogenic scattering and backscattering are obtained by subtracting bio $b_{p}$ and ${ }_{b i o} b_{b p}$ obtained 293 from Eqs. 14 and 15 from observed $b_{p}$ and $b_{b p}$ for Case 2 stations. Best-fit power law regression 294 of these nonbiogenic partial IOPs against $T S S_{\text {nonbio }}$ (Figure 3) gives relationships of the form:

$$
{ }_{\text {nonbio }} a_{\text {nap }}(\lambda)=A_{1}(\lambda) T S S_{\text {nonbio }}^{B_{1}(\lambda)}
$$

296

$$
{ }_{\text {nonbio }} b_{p}(\lambda)=A_{2}(\lambda) T S S_{\text {nonbio }}^{B_{2}(\lambda)}
$$

297

$$
{ }_{\text {nonbio }} b_{b p}(\lambda)=A_{3}(\lambda) T S S_{\text {nonbio }}^{B_{3}(\lambda)}
$$

$298 A_{i}(\lambda)$ and $B_{i}(\lambda)$ coefficients for these relationships and their regression coefficients are provided 299 in Table 1. 

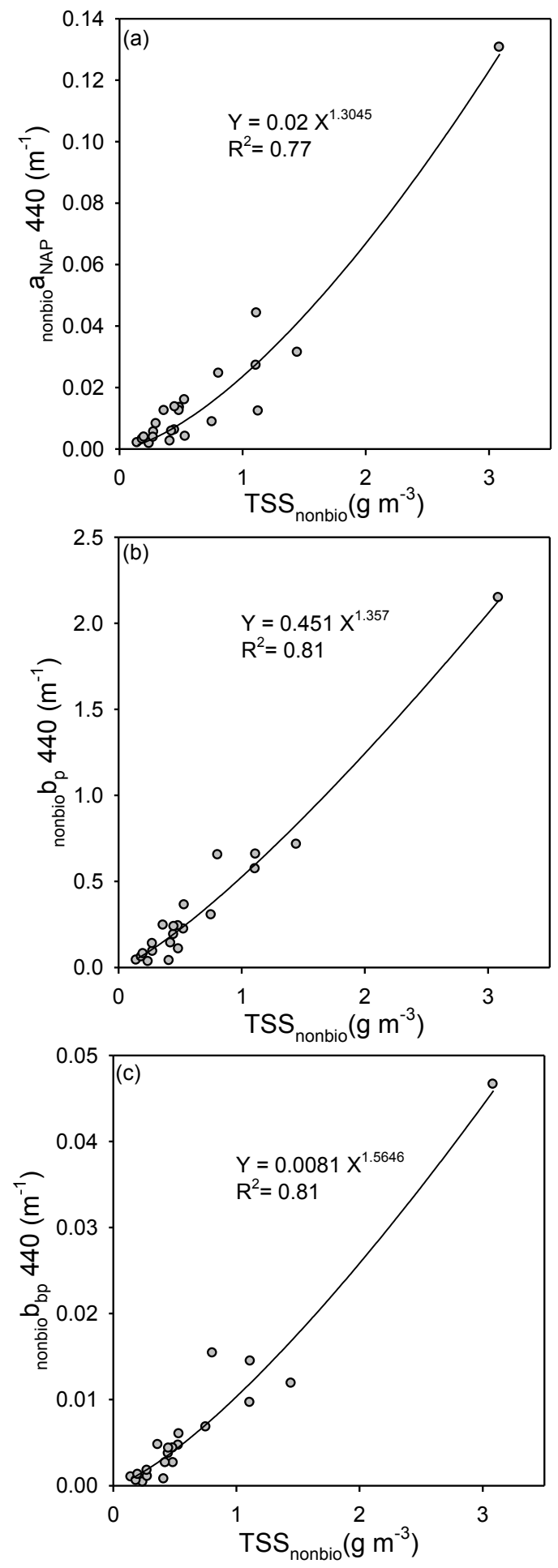

301 Figure 3. Non-biogenic components of (a) non-algal particulate absorption, (b) particulate 302 scattering and (c) particulate backscattering, all at $440 \mathrm{~nm}$ plotted against the non-biogenic 303 component of TSS. Spectrally resolved best-fit parameters are given in Table 1. 

absorption associated with freshwater inputs into the Ligurian Sea that are not associated with algal properties. Figure $4 \mathrm{~b}$ shows a global relationship between CDOM absorption and salinity 308 from the NOMAD data set. Low salinity values are associated with regions of stronger 309 freshwater input with higher levels of CDOM absorption. The Mediterranean Sea has very 310 restricted exchange with the global ocean and evaporation rates exceed freshwater inputs 311 leading to unusually high salinity levels, as seen in the relatively high values for the BP09 data 312 included in Figure 4b. As a result, a small offset was added to the global salinity - CDOM 313 relationship for operation in the relatively high salinity waters of the Mediterranean Sea, giving

$$
{ }_{\text {nonbio }} a_{\text {CDOM }}(440)=0.73-0.018 \times \text { Salinity }
$$

This nonbiogenic component of CDOM absorption is only invoked when salinity drops below

316 a threshold value of 37 PSU, in which case

$$
a_{C D O M}(440)=_{\text {bio }} a_{\text {CDOM }}(440)+{ }_{\text {nonbio }} a_{\text {CDOM }}(440)
$$

while the wavelength dependence of CDOM absorption (biogenic and nonbiogenic) is given

319 by Eq. 12.

321 Table 1. Coefficient values for nonbio $_{\text {nap }}(\lambda)$, nonbio $b_{p}(\lambda)$ and nonbio $_{b p}(\lambda)$. Regression coefficients

322 are also presented for biogenic absorption coefficient without water $\left({ }_{b i o} a=a_{p h}+{ }_{b i o} a_{a p}+\right.$

323 bio $\left.a_{C D O M}\right)$, biogenic particulate scattering coefficient $\left({ }_{b i o} b_{p}\right)$ and biogenic particulate

\begin{tabular}{|c|c|c|c|c|c|c|c|c|c|c|c|}
\hline \multirow{2}{*}{$\begin{array}{c}\text { Y } \\
\text { Variable }\end{array}$} & \multirow{2}{*}{$\begin{array}{c}\mathrm{X} \\
\text { Variable }\end{array}$} & \multirow[b]{2}{*}{ Equation } & \multirow{2}{*}{ Coefficients } & \multicolumn{8}{|c|}{ Wavelengths (nm) } \\
\hline & & & & 412 & 440 & 488 & 510 & 532 & 555 & 650 & 676 \\
\hline bioa & Chl & $8-12$ & $\mathbf{R}^{2}$ & 0.84 & 0.84 & 0.83 & 0.8 & 0.78 & 0.72 & 0.78 & 0.82 \\
\hline${ }_{b i o} b_{p}$ & Chl & 13 & $\mathbf{R}^{2}$ & 0.72 & 0.71 & 0.71 & 0.71 & 0.71 & 0.71 & 0.68 & 0.67 \\
\hline${ }_{b i o} b_{b p}$ & Chl & 14 & $\mathbf{R}^{2}$ & 0.42 & 0.41 & 0.43 & 0.43 & 0.45 & 0.47 & 0.46 & 0.53 \\
\hline \multirow{2}{*}{ nonbioanap } & \multirow{2}{*}{ TSS $S_{\text {nonbio }}$} & & $A_{1}(\lambda)$ & 0.028 & 0.02 & 0.013 & 0.013 & 0.011 & 0.009 & 0.007 & 0.002 \\
\hline & & 17 & $\mathbf{B}_{1}(\lambda)$ & 1.405 & 1.3045 & 1.45 & 1.49 & 1.065 & 1.26 & 0.87 & 0.85 \\
\hline
\end{tabular}

324 backscattering coefficient $\left({ }_{b i o} b_{b p}\right)$. 


\begin{tabular}{|c|c|c|c|c|c|c|c|c|c|c|c|}
\hline & & & $\mathbf{R}^{2}$ & 0.81 & 0.77 & 0.83 & 0.8 & 0.82 & 0.84 & 0.67 & 0.62 \\
\hline \multirow{3}{*}{${ }_{n o n b i o} b_{p}$} & \multirow{3}{*}{$T_{S S_{\text {nonbio }}}$} & \multirow{3}{*}{18} & $A_{2}(\lambda)$ & 0.446 & 0.451 & 0.43 & 0.442 & 0.4452 & 0.455 & 0.435 & 0.391 \\
\hline & & & $\mathbf{B}_{2}(\lambda)$ & 1.4167 & 1.357 & 1.3135 & 1.265 & 1.2566 & 1.22 & 1.245 & 1.342 \\
\hline & & & $\mathbf{R}^{2}$ & 0.83 & 0.81 & 0.87 & 0.88 & 0.83 & 0.82 & 0.86 & 0.85 \\
\hline \multirow{3}{*}{${ }_{n o n b i o} b_{b p}$} & \multirow{3}{*}{$T S S_{\text {nonbio }}$} & \multirow{3}{*}{19} & $\mathbf{A}_{3}(\lambda)$ & 0.0091 & 0.0081 & 0.0087 & 0.009 & 0.0081 & 0.007 & 0.008 & 0.006 \\
\hline & & & $\mathbf{B}_{3}(\lambda)$ & 1.48 & 1.5646 & 1.3095 & 1.264 & 1.263 & 1.245 & 1.416 & 1.154 \\
\hline & & & $\mathbf{R}^{2}$ & 0.8 & 0.81 & 0.83 & 0.84 & 0.84 & 0.84 & 0.83 & 0.82 \\
\hline
\end{tabular}
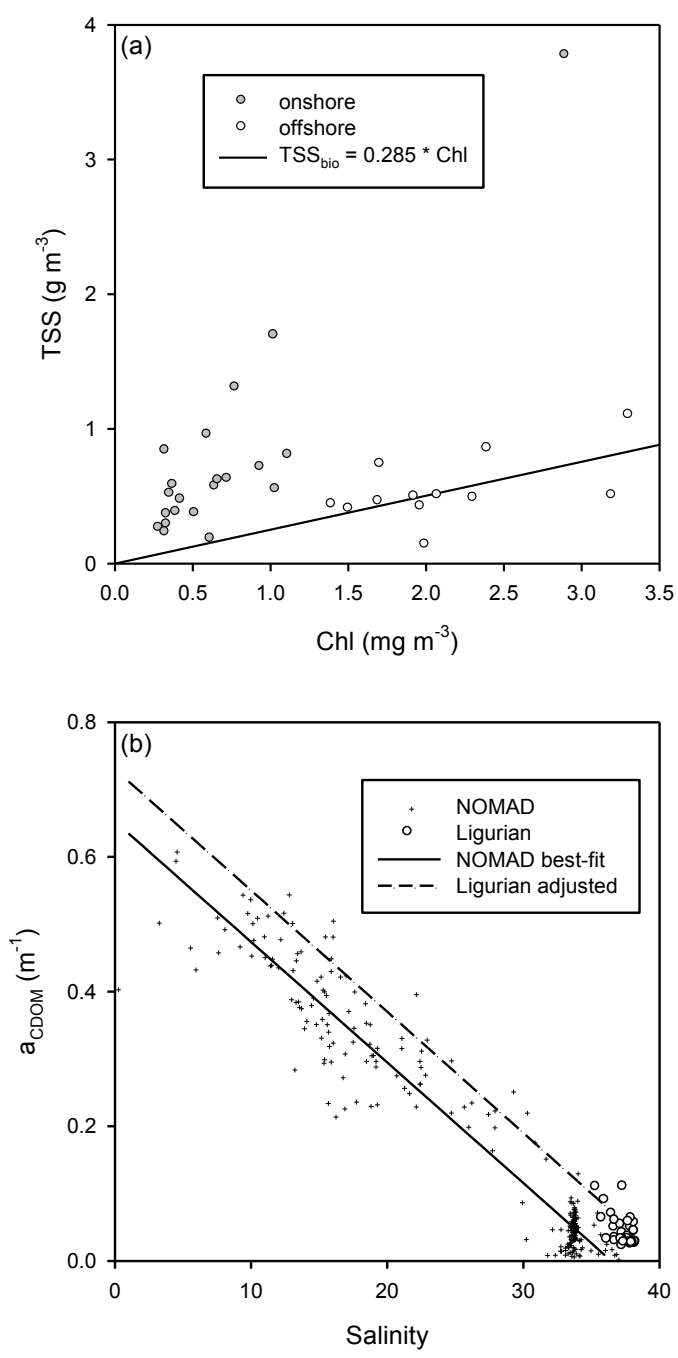

328 Figure 4 (a) Relationship between TSS and Chl for onshore and offshore stations. Black line

329 shows the relation between $T S S_{p h}$ and $C h l$ for offshore stations (best-fit regression, forced 330 through zero, $\mathrm{R}^{2}=0.29$ ). (b) Relationship between $a_{C D O M}(440)$ and salinity measurements for 331 the NOMAD (black circles) and Ligurian Sea (white circles) data sets. The solid line shows 
332 the best fit for the NOMAD data set $\left(\mathrm{R}^{2}=0.91\right)$, and the dashed line shows the offset-adjusted 333 relationship for the Ligurian Sea.

\subsection{Bio-optical model validation strategy}

The aim of this work is to develop a bio-optical model that will ultimately be incorporated into a Ligurian Sea ecosystem model to improve prediction of underwater light fields and associated impacts on phytoplankton photosynthesis and solar heating. Data for assimilation into and validation of the ecosystem model may ultimately come from a variety of sources including satellite remote sensing and/or in situ observations from moorings (static or

341 profiling) or autonomous vehicle platforms (Trees et al. 2009). In each case there is a need to 342 adopt common currencies between external data observations and the ecosystem model. In this work, these common currencies have been selected to be Chl, TSS and Salinity. Here simple

344 linear calibrations are applied to turbidity and fluorescence data collected on CTD profiles to generate proxy profiles of TSS and Chl. Together with $a_{C D O M}$ values derived from Salinity 346 profiles, this provides us with an independent set of estimates of OSCs for depths where direct measurements of these parameters were not available. These OSC estimates are then passed into the bio-optical model to generate estimates of partial IOPs for each constituent as depth profiles, and final validation is by comparing estimated total non-water IOPs against directly measured values. By operating on depth profile data, the validation uses thousands of data

351 points for which no OSC measurements were available and IOP data that was not used in the 352 bio-optical model derivation. It also tests the applicability of using simple proxies (Turbidity, 353 Fluorescence and Salinity) to estimate OSCs, including extension into sub-pycnocline and sub354 euphotic zone waters where there is a reasonable expectation that such relationships might 355 vary. In this work the data has been partitioned by geographical location, with offshore stations 356 regarded as Case 1 and onshore stations regarded as Case 2. In future it would be possible to 
357 further refine the assignment of Case 1/2 status using derived values of TSS and Chl to 358 determine whether to use Case 1 or Case 2 bio-optical models for the particulate component of 359 IOPs, with the bifurcation in Figure 4a acting as a simple threshold differentiator. Similarly, 360 Salinity data reveals whether or not there is a significant freshwater influence and if a 361 nonbiogenic component of CDOM absorption is required. Validation of the proposed bio-optical model is therefore in four steps (Figure 5):

1. CTD + fluorescence + turbidity profiles provide Salinity and estimates of $C h l$ and TSS.

4. Modelled radiometric data are compared against in situ measurements.

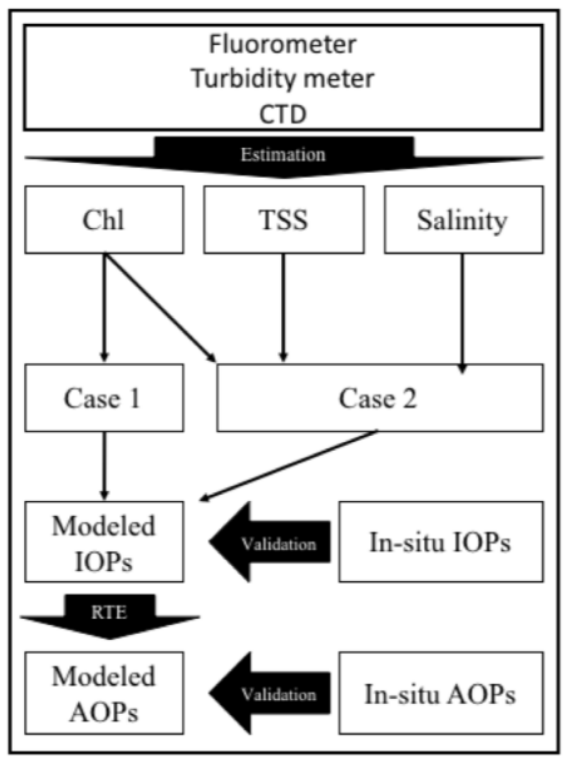

370 Figure 5. Flow chart for validation of the proposed bio-optical model. NB. This approach

371 extends the validation data set to include thousands of data points that could not be used in 372 model derivation as discrete water samples were limited to a small number of surface stations 373 only. 
375 This optical closure approach using in situ $E_{d}$ and $L_{u}$ data for model validation provides a rigorous test of the bio-optical model and its implementation with a proxy data input method, and therefore gives a relatively strong indication of the level of performance that might be achievable from such a system in practise.

\section{Results}

\subsection{Bio-optical model validation}

Turbidity and fluorescence sensors were calibrated with surface TSS and Chl data from across the region, using data from 35 and 32 stations, respectively. The data ranged between $0.29 \mathrm{mg} \mathrm{m}^{-3}$ and $3.31 \mathrm{mg} \mathrm{m}^{-3}$ for $C h l$, and $0.13 \mathrm{mg} \mathrm{l}^{-1}$ and $3.77 \mathrm{mg}^{-1}$ for TSS. Significant linear relationships were found between turbidity values and $T S S\left(\mathrm{R}^{2}=0.85\right)$, and between fluorescence values and $C h l\left(\mathrm{R}^{2}=0.71\right)$. These calibrations were used to generate estimated profiles of $C h l$ and TSS from CTD fluorescence and turbidity profiles, which, along with CTD

Salinity profiles, are sufficient to parameterise the Ligurian Sea bio-optical model as described above. The performance of the bio-optical model was determined by comparison with corresponding IOP data obtained from in situ AC-9 and BB9 measurements (see Table 2 for descriptive statistics for these measurements). The subsequent performance of Ecolight radiative transfer simulations using the Ligurian Sea bio-optical model as input was assessed against in situ radiometric measurements (downwards irradiance $E_{d}$ and upwards radiance $L_{u}$ )

394 and derived apparent optical properties (downwards diffuse attenuation coefficient $K_{d}$ and 395 radiance reflectance $R_{L}$ ). Lefering et al. (2016) provides further details of the Ecolight model parameterization used.

398 Table 2. Descriptive statistics of the in situ data from AC-9 and BB9 instruments $\left(a_{n w}=a_{t}-a_{w}\right.$ $399=$ non-water absorption coefficient, $b_{p}=$ particulate scattering coefficient, $b_{b p}=$ particulate 


\begin{tabular}{|c|c|c|c|c|c|c|c|c|c|}
\hline \multirow{2}{*}{ Variable } & \multirow{2}{*}{ Parameter } & \multicolumn{8}{|c|}{ Wavelength (nm) } \\
\hline & & 412 & 440 & 488 & 510 & 532 & 555 & 650 & 676 \\
\hline \multirow{3}{*}{$a_{n w}\left(\mathbf{m}^{-1}\right)$} & Mean & 0.0891 & 0.0688 & 0.0410 & 0.0293 & 0.0225 & 0.0140 & 0.0066 & 0.0175 \\
\hline & Max & 0.6551 & 0.5402 & 0.3407 & 0.2646 & 0.2050 & 0.1429 & 0.0706 & 0.1606 \\
\hline & Min & 0.0013 & 0.0000 & 0.0000 & 0.0000 & 0.0000 & 0.0000 & 0.0000 & 0.0010 \\
\hline \multirow{3}{*}{$b_{p}\left(\mathrm{~m}^{-1}\right)$} & Mean & 0.4538 & 0.4402 & 0.4298 & 0.4265 & 0.4201 & 0.4175 & 0.3777 & 0.3513 \\
\hline & Max & 3.5746 & 3.5041 & 3.3555 & 3.2637 & 3.1909 & 3.1447 & 2.9598 & 2.7735 \\
\hline & Min & 0.0337 & 0.0302 & 0.0292 & 0.0263 & 0.0266 & 0.0259 & 0.0218 & 0.0158 \\
\hline \multirow{3}{*}{$b_{b p}\left(\mathbf{m}^{-1}\right)$} & Mean & 0.0086 & 0.0078 & 0.0079 & 0.0084 & 0.0074 & 0.0071 & 0.0069 & 0.0062 \\
\hline & Max & 0.0932 & 0.0849 & 0.0837 & 0.0867 & 0.0775 & 0.0747 & 0.0732 & 0.0637 \\
\hline & Min & 0.0006 & 0.0006 & 0.0007 & 0.0010 & 0.0008 & 0.0007 & 0.0006 & 0.0005 \\
\hline
\end{tabular}
observed between model results and in situ data for each variable at all wavelengths. The highest correlation, 0.88 , was observed for absorption and particulate backscattering at $676 \mathrm{~nm}$, while the lowest correlation, 0.78 , was observed for scattering at $676 \mathrm{~nm}$. The range of model error for each IOP is given in Table 3, along with mean and root mean square errors (Eq. 22of points that could be described as outliers, but that would, in practice, be part of an input data 411 set. The mean error (Eq. 22) is a useful indicator of model bias, and shows, for example, a 412 tendency for the bio-optical model to over-estimate absorption in the blue. In general, mean 413 error values are low indicating low bias over all. That said, Figure 6 shows that there is a 414 tendency to over-estimate particulate scattering at low values $\left(<0.2 \mathrm{~m}^{-1}\right)$ and underestimate at 415 high values $\left(0.2-1 \mathrm{~m}^{-1}\right)$. The root mean square error (RMSE, Eq. 23) provides typical error 416 magnitudes for each parameter. RMSE values vary spectrally from 0.03 to $0.006 \mathrm{~m}^{-1}$ for 417 absorption, but are spectrally invariant at $\sim 0.165 \mathrm{~m}^{-1}$ and $\sim 0.003 \mathrm{~m}^{-1}$ for particulate scattering and backscattering respectively. 


$$
R M S E=\sqrt{\frac{1}{n} \sum_{i=1}^{n}\left(y_{i}-y_{i}^{\prime}\right)^{2}}
$$

421 where $y$ and $y^{\prime}$ are modelled and measured values respectively.

422 Table 3. Statistical comparison of the in situ and modelled IOP data sets.

\begin{tabular}{|c|c|c|c|c|c|c|c|c|}
\hline \multirow{3}{*}{ Statistics } & \multicolumn{8}{|c|}{ Wavelengths (nm) } \\
\hline & 412 & 440 & 488 & 510 & 532 & 555 & 650 & 676 \\
\hline & \multicolumn{8}{|c|}{ anw } \\
\hline Minimum error & -0.207 & -0.140 & -0.116 & -0.109 & -0.099 & -0.069 & -0.021 & -0.064 \\
\hline Maximum error & 0.172 & 0.156 & 0.094 & 0.111 & 0.038 & 0.046 & 0.026 & 0.045 \\
\hline Mean error & 0.010 & 0.015 & 0.008 & 0.005 & 0.002 & 0.004 & 0.005 & 0.001 \\
\hline Root mean square error & 0.032 & 0.029 & 0.017 & 0.013 & 0.009 & 0.008 & 0.006 & 0.007 \\
\hline \multirow[t]{2}{*}{ Linear correlation $(\mathbf{r})$} & 0.82 & 0.84 & 0.84 & 0.81 & 0.82 & 0.79 & 0.84 & 0.88 \\
\hline & \multicolumn{8}{|c|}{$\mathbf{b}_{\mathbf{p}}$} \\
\hline Minimum error & -2.012 & -1.983 & -2.064 & -2.079 & -2.088 & -2.101 & -2.019 & -1.895 \\
\hline Maximum error & 2.054 & 1.698 & 1.290 & 1.160 & 1.177 & 1.089 & 1.297 & 1.575 \\
\hline Mean error & 0.013 & 0.008 & -0.017 & -0.026 & -0.031 & -0.037 & -0.035 & -0.027 \\
\hline Root mean square error & 0.163 & 0.156 & 0.160 & 0.164 & 0.168 & 0.172 & 0.166 & 0.157 \\
\hline \multirow[t]{2}{*}{ Linear correlation $(r)$} & 0.83 & 0.84 & 0.83 & 0.82 & 0.81 & 0.80 & 0.78 & 0.77 \\
\hline & \multicolumn{8}{|c|}{$\mathbf{b}_{\text {bp }}$} \\
\hline Minimum error & -0.056 & -0.053 & -0.053 & -0.055 & -0.044 & -0.041 & -0.045 & -0.040 \\
\hline Maximum error & 0.038 & 0.048 & 0.015 & 0.010 & 0.011 & 0.010 & 0.029 & 0.005 \\
\hline Mean error & 0.000 & 0.000 & -0.001 & -0.002 & 0.000 & 0.000 & -0.001 & -0.001 \\
\hline Root mean square error & 0.004 & 0.003 & 0.003 & 0.004 & 0.003 & 0.003 & 0.003 & 0.002 \\
\hline Linear correlation $(r)$ & 0.82 & 0.79 & 0.84 & 0.85 & 0.84 & 0.84 & 0.82 & 0.87 \\
\hline
\end{tabular}

423 

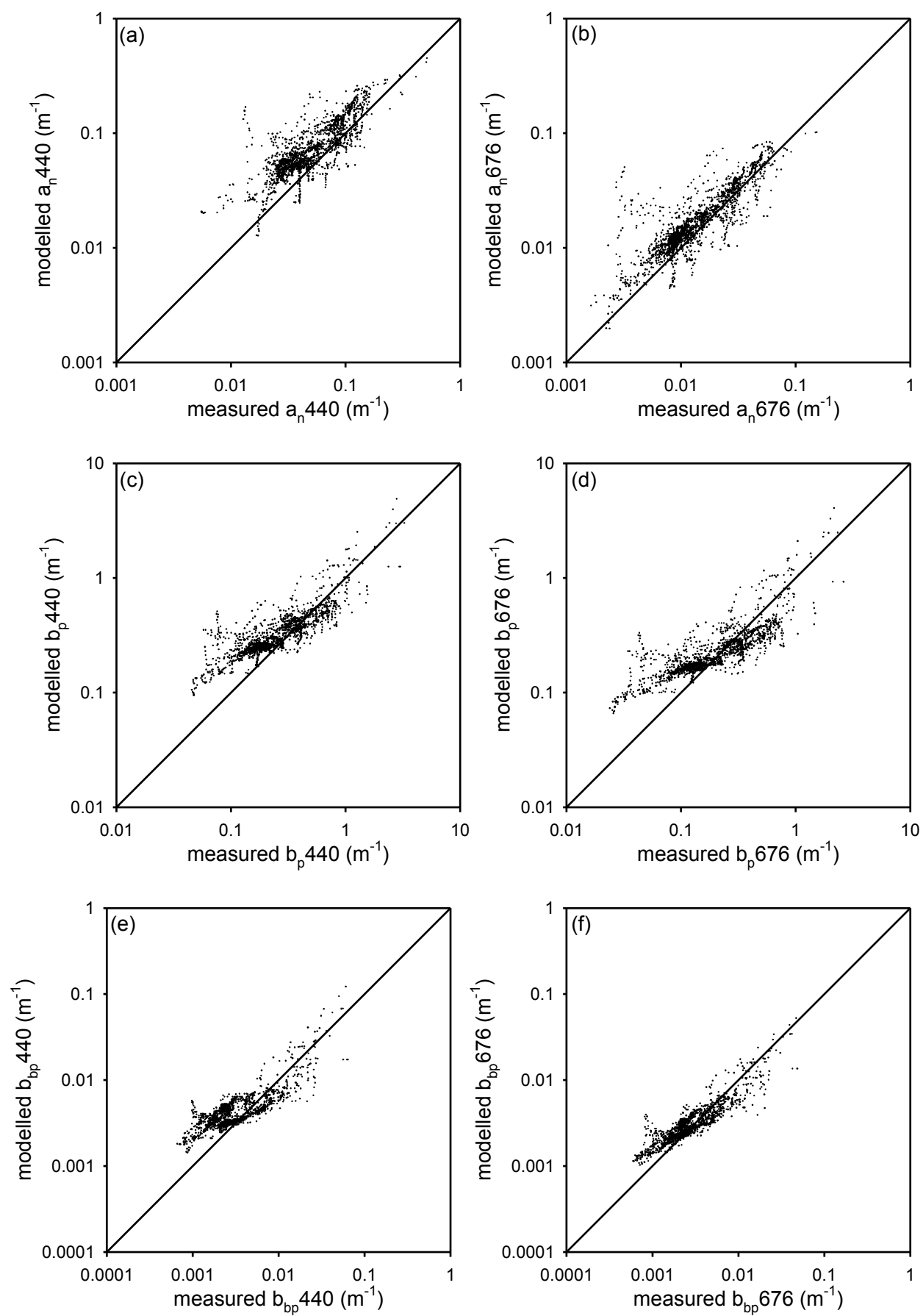

Figure 6. Comparisons of modeled and measured: non-water absorption (a) and (b),

427 particulate scattering (c) and (d), and particulate backscattering (e) and (f) for blue (440 nm)

428 and red $(676 \mathrm{~nm})$ wavelengths. 
432 Scientific Inc.) parameterised using the bio-optical model described above, together with

433 measured above-surface downwards irradiance values and solar zenith angles. Simulated

434 underwater radiometry outputs were validated against in situ spectral $E_{d}$ and $L_{u}$ measurements

$435(\mathrm{~N}=452)$ and integrated $(400-700 \mathrm{~nm})$ photosynthetically available radiation, $E_{P A R}$ and $L_{P A R}$

436 for all available depths (Figure 7). Correlations between modelled and measured radiometric variables were generally very high $(>0.85$, Table 4$)$ with $E_{d}$ generally performing better than $L_{u}$. Both $E_{d}$ and $L_{u}$ were systematically under-estimated at $676 \mathrm{~nm}$, which is most likely a consequence of not including chlorophyll fluorescence in the radiative transfer simulations.

440 The impact of this bias in the simulation of red wavelength radiometry on PAR estimates is 441 very weak, with both $E_{P A R}$ and $L_{P A R}$ having low bias and RMSE errors. $E_{P A R}$ profiles were used 442 to calculate $1 \%$ and $10 \%$ light depths (euphotic and mid-euphotic depths respectively, Figure 443 8). These data showed significant correlations and low errors, with maximum errors of $6 \mathrm{~m}$ in 444 euphotic depth, and $8 \mathrm{~m}$ in mid-euphotic depth. With RMSE errors of $3.2 \mathrm{~m}$ and $2.6 \mathrm{~m}$ in 445 euphotic and mid-euphotic depths, respectively, it is clear that the integrated bio-optical / 446 radiative transfer model provides a reasonable representation of the penetration of spectrally averaged sunlight with depth.

Figure 9 shows excellent correlations between measured and modeled radiance reflectance profile data where

$$
R_{L}(\lambda)=L_{u}(\lambda, z) / E_{d}(\lambda, z)
$$

451 with the exception of $676 \mathrm{~nm}$ where modelled values are significantly lower than 452 measurements, probably due to non-inclusion of algal fluorescence in the simulations. 453 Comparison of modelled surface remote sensing reflectance

$$
R_{r s}(\lambda)=L_{w}\left(\lambda, 0^{+}\right) / E_{d}\left(\lambda, 0^{+}\right)
$$

455 with MERIS C2R data (Figure 10) also shows strong correlations except for $620 \mathrm{~nm}$, where 
modelled values are significantly overestimated. In this case, the discrepancy is probably a

457 consequence of inappropriate interpolation of input IOP data (555 and $650 \mathrm{~nm}$ are the nearest

458 input wavebands), leading to a poor parameterisation of the radiative transfer model.

459 Comparisons with other satellite data were less convincing, possibly reflecting sensitivity to

460 selection of atmospheric correction scheme and fidelity of match-up conditions.

461

462 Table 4. Statistical comparison of in situ and modeled radiometry values.

\begin{tabular}{|c|c|c|c|c|c|c|c|c|c|}
\hline \multirow{3}{*}{ Statistics } & \multicolumn{9}{|c|}{ Wavelengths (nm) } \\
\hline & 412 & 440 & 488 & 510 & 532 & 555 & 650 & 676 & PAR \\
\hline & \multicolumn{9}{|c|}{ Ed } \\
\hline Minimum error & -0.2593 & -0.2621 & -0.2217 & -0.1950 & -0.1624 & -0.1399 & -0.1023 & -0.1262 & $-1.00 \mathrm{E}+20$ \\
\hline Maximum error & 0.1770 & 0.1677 & 0.2166 & 0.2038 & 0.2151 & 0.2177 & 0.1417 & 0.0962 & $1.00 \mathrm{E}+20$ \\
\hline Mean error & 0.0132 & 0.0083 & 0.0188 & 0.0036 & -0.0012 & -0.0040 & -0.0108 & -0.0142 & $-4.67 \mathrm{E}+17$ \\
\hline $\begin{array}{l}\text { Root mean square } \\
\text { error }\end{array}$ & 0.0673 & 0.0656 & 0.0676 & 0.0552 & 0.0493 & 0.0447 & 0.0280 & 0.0289 & $4.74 \mathrm{E}+19$ \\
\hline \multirow[t]{2}{*}{ Linear correlation $(\mathbf{r})$} & 0.95 & 0.97 & 0.97 & 0.98 & 0.98 & 0.98 & 0.99 & 0.98 & 0.96 \\
\hline & \multicolumn{9}{|c|}{ Lu } \\
\hline Minimum error & -0.0024 & -0.0031 & -0.0043 & -0.0044 & -0.0037 & -0.0042 & -0.0014 & -0.0012 & $-2.00 \mathrm{E}+18$ \\
\hline Maximum error & 0.0047 & 0.0037 & 0.0021 & 0.0011 & 0.0024 & 0.0020 & 0.0004 & 0.0000 & $1.00 \mathrm{E}+18$ \\
\hline Mean error & 0.0005 & 0.0001 & -0.0005 & -0.0008 & -0.0001 & -0.0002 & -0.0001 & -0.0002 & $-1.41 \mathrm{E}+17$ \\
\hline $\begin{array}{l}\text { Root mean square } \\
\text { error }\end{array}$ & 0.0013 & 0.0010 & 0.0012 & 0.0012 & 0.0009 & 0.0009 & 0.0002 & 0.0002 & $5.55 \mathrm{E}+17$ \\
\hline Linear correlation $(r)$ & 0.92 & 0.93 & 0.93 & 0.95 & 0.93 & 0.92 & 0.91 & 0.85 & 0.89 \\
\hline
\end{tabular}

463

464 

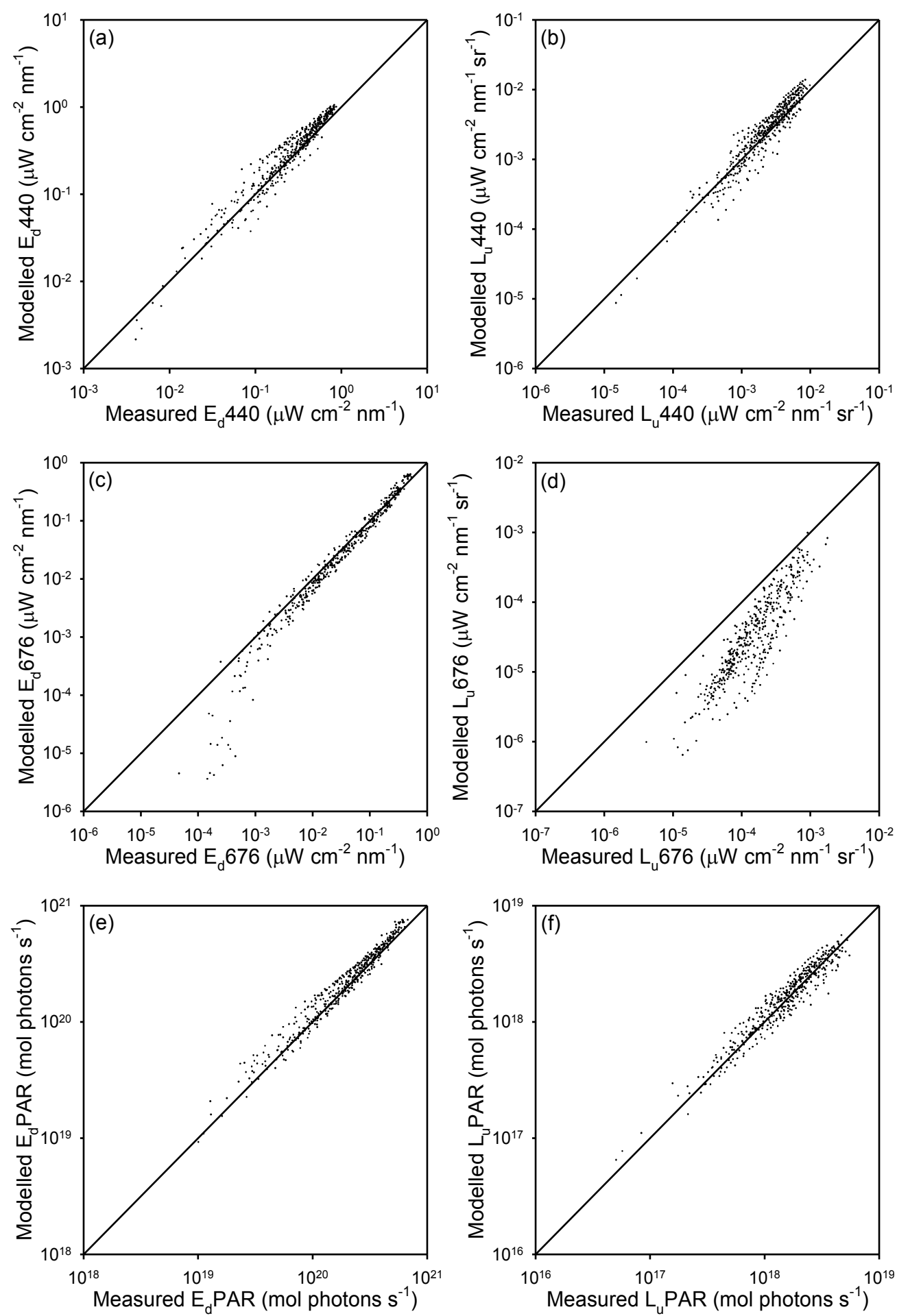

Figure 7. Comparisons of modeled and measured profiles of downwards irradiance, $E_{d}$, and

467 upwards radiance, $L_{u}$, for blue $(440 \mathrm{~nm})$ and red $(676 \mathrm{~nm})$ wavelengths, and integrated across

468 the photosynthetically active region, PAR $(400-700 \mathrm{~nm})$. 


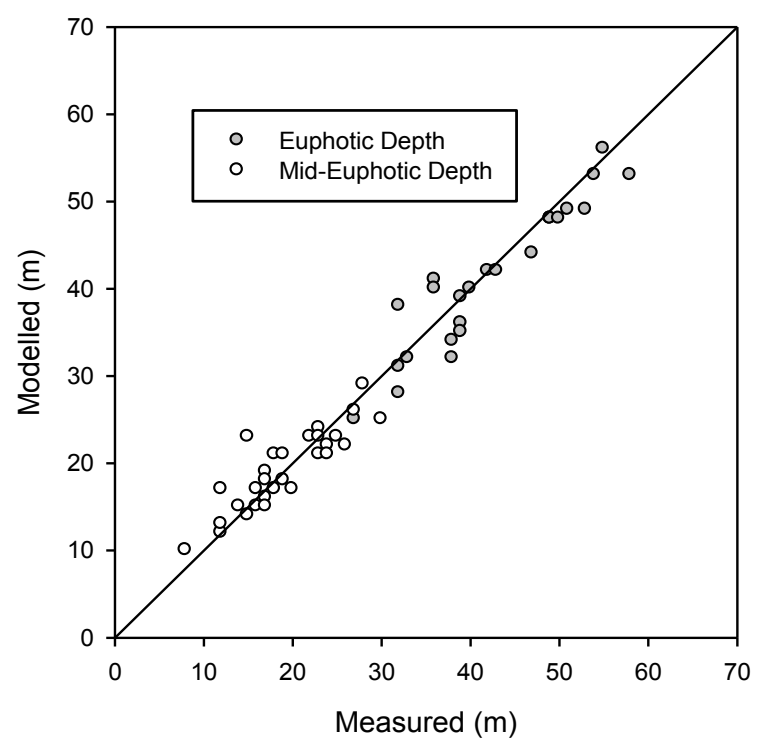

471 Figure 8. Comparison of modelled and measured euphotic and mid-euphotic depths. NB In-

472 situ radiometry measurements did not always reach the euphotic depth, reducing the number 473 of data points on this plot.
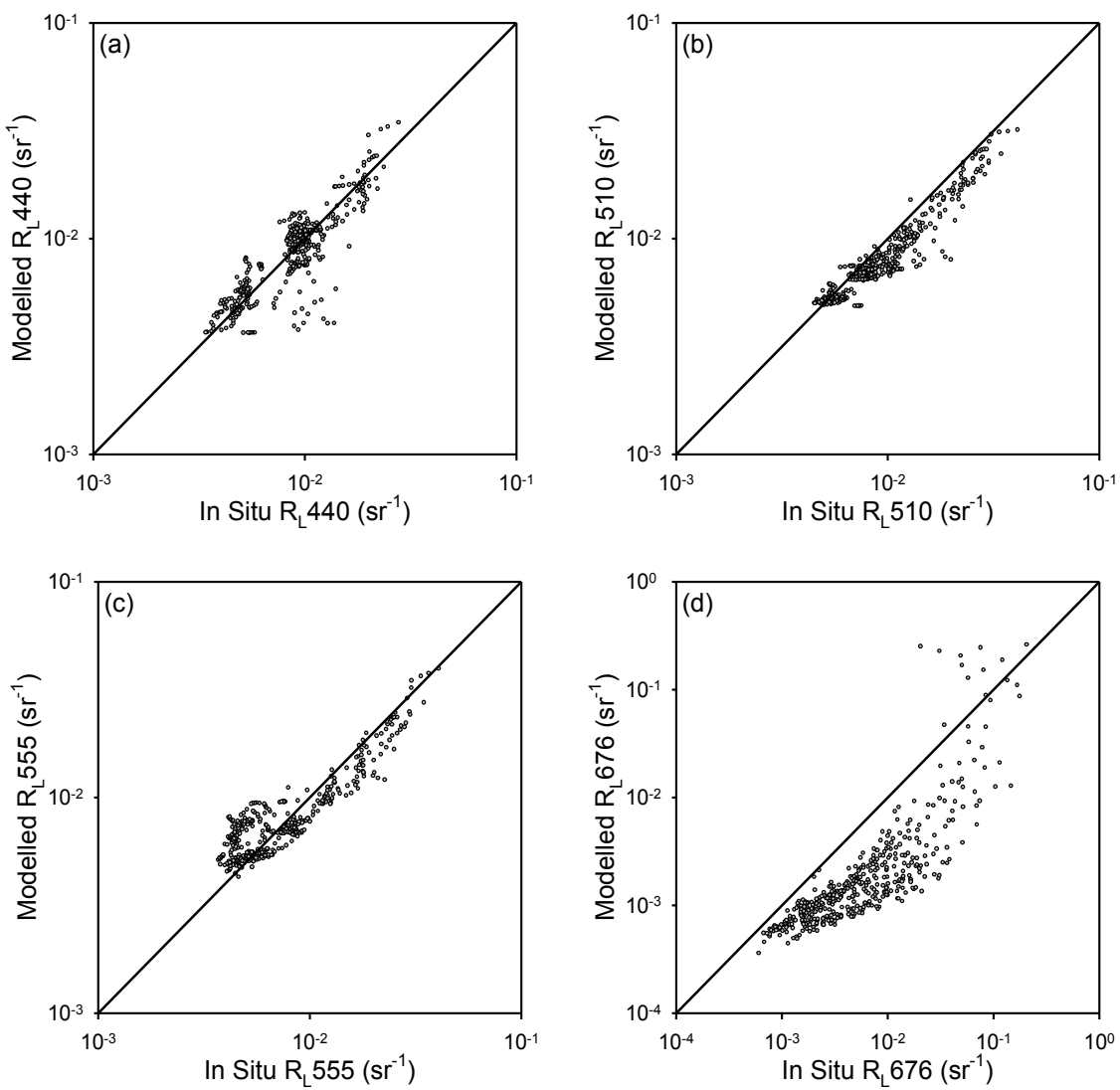

Figure 9. (a-c) Modelled profiles of radiance reflectance generally correlate well with in situ 
476 measurements in the blue - green. (d) The model under-estimates red radiance reflectance as 477 it does not include the effect of chlorophyll fluorescence.
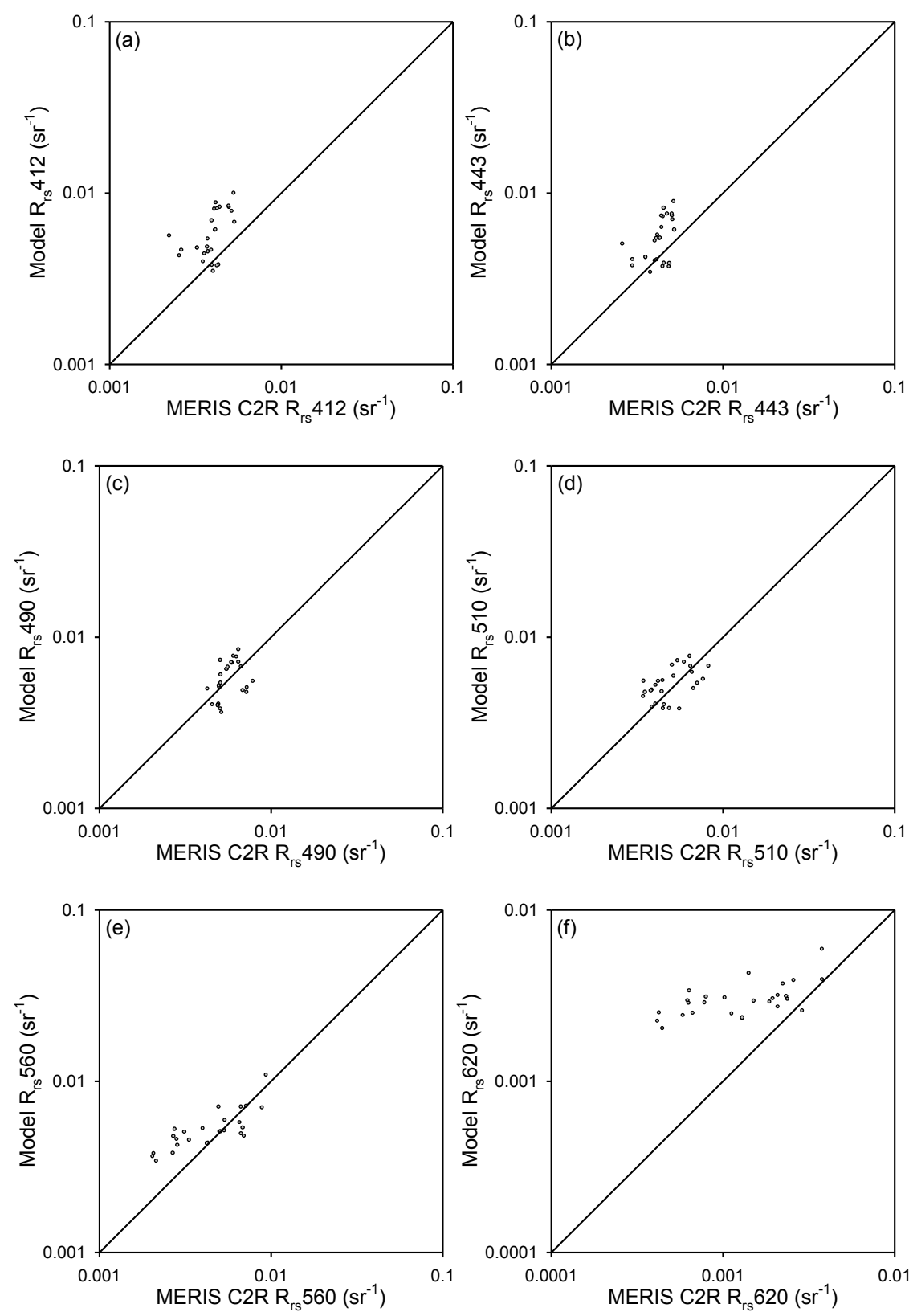

480 Figure 10. (a-e) Modelled above surface remote sensing reflectance corresponds well with

481 MERIS data processed using the C2R algorithm for wavelengths in the blue-green. (f) Model 482 performance is less satisfactory at $620 \mathrm{~nm}$, potentially as a result of inadequate interpolation of 483 input data to the model (555 and $650 \mathrm{~nm}$ the nearest input wavebands). NB. Includes data from 484 both onshore and offshore stations. 


\section{Discussion and Conclusion}

been shown to provide an effective characterization of the optical properties of the region. In

doing so, it is worth considering the various stages of model development that have been incorporated into the validation scheme. Although the Case 1 elements of the bio-optical model are relatively standard, the Case 2 section contains several innovations including statistical partitioning of TSS and derivation of partial IOPs for non-biogenic particles. It also includes a separation of CDOM contributions from biogenic (effectively phytoplankton) and non-

494 biogenic (freshwater) sources. A scheme for partitioning the region into Case 1, Case 2 (non-

495 biogenic particles) and Case 2 (freshwater influence) zones based on Chl, TSS and Salinity values has been presented which is essential for correctly selecting the appropriate bio-optical model for any given point in space. It is also worth emphasizing that the performance of the model has been demonstrated using proxy values of Chl and TSS derived from in situ fluorescence and turbidity measurements, which introduces another set of measurement uncertainties into the analysis. The resulting comparisons with in situ IOP data are therefore particularly encouraging given this added layer of data manipulation. in this case Salinity, Fluorescence and Turbidity from CTD profiles) into IOP profiles and

504 ultimately allow estimation of spectral remote sensing reflectance. There are two crucial early 505 steps that need to be treated with due caution: (1) conversion of these simple proxies into OSC concentrations, and (2) selection of Case 1 or Case 2 bio-optical models for any given data 507 point. There is considerable scope for further refinement of both steps beyond the very simple 508 approach adopted here. For example, there are many potential options for partitioning water 509 masses using combinations of IOP, constituent data and other physical variables (McKee and 
511 The utility of this bio-optical model for predicting underwater and water-leaving light

512 fields has been tested through rigorous optical closure analysis against in situ and remotely

513 sensed radiometry and AOPs. When considering the level of performance achieved, it should

514 be recognized that direct optical closure between in situ IOPs and radiometry remains elusive

515 and rarely demonstrated to date (Tzortziou et al. 2006). The degree of closure demonstrated

516 here is therefore very encouraging and suggests that major features of the optical characteristics

517 of the region have been satisfactorily captured in the bio-optical model.
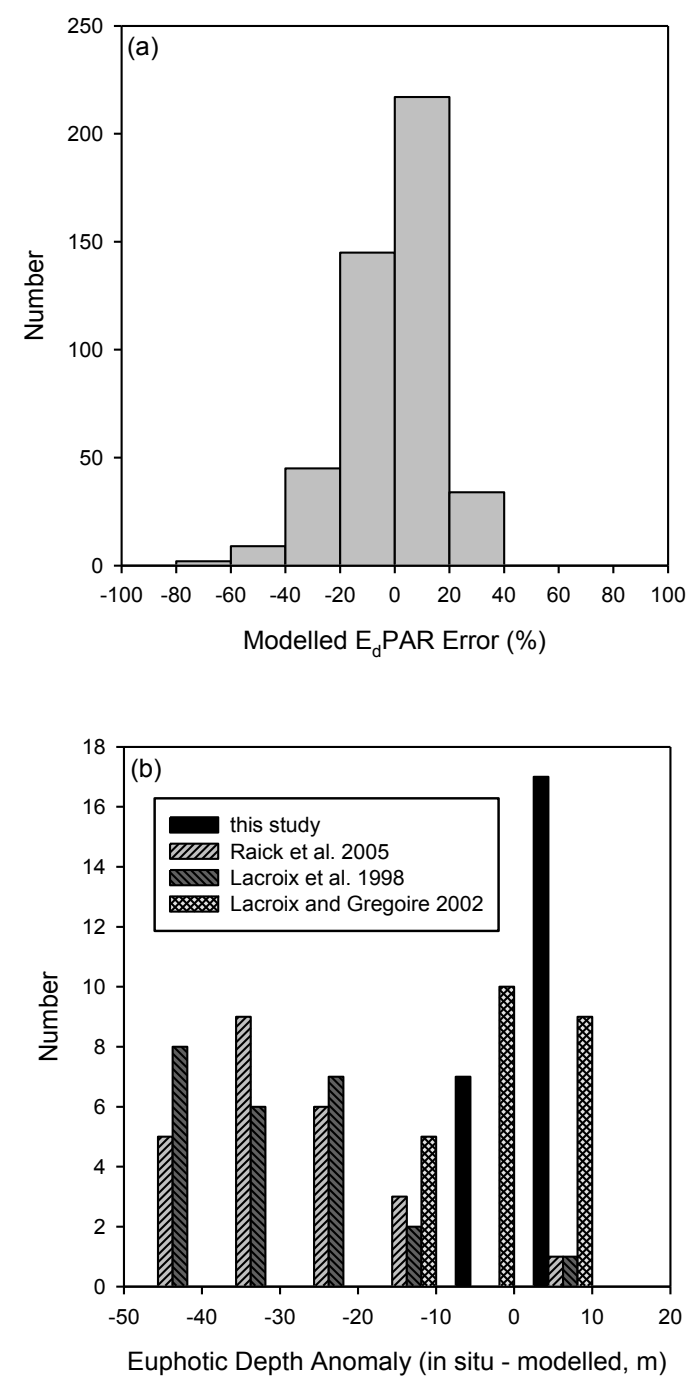

Euphotic Depth Anomaly (in situ - modelled, m)

Figure 11. (a)Percentage error of modeled $E_{d} P A R$ values using approach presented 
522 here. (b) Anomaly of modelled euphotic depths for the approach developed here and previous 523 studies.

524 A major motivation for this work is to develop a bio-optical model that can be 525 incorporated into radiative transfer simulations to provide accurate predictions of underwater 526 photosynthetically available radiation. Figure 11a shows the distribution of percentage errors 527 in modeled PAR $\left(E_{d}\right)$ across all available stations and depths for this data set, with $80 \%$ of 528 points falling within $\pm 20 \%$ and a $95 \%$ prediction interval of $\pm 33 \%$. Predictions of euphotic 529 depth from the approach developed here compare favourably (Figure 11b) against values 530 calculated from previous approaches of Lacroix \& Nival 1998, and Raick et al. 2005 which do 531 not account for non-algal contributions. The Lacroix \& Gregoire (2002) model is closer in 532 performance to the model developed here, benefitting from a slightly more representative 533 underwater light field model than the earlier study. However, analysis of performance 534 separating into onshore and offshore groups (Figure 12) highlights the benefit of directly 535 accounting for both non-biogenic particles and freshwater sources of CDOM for modeling 536 euphotic depth in optically complex onshore stations. 

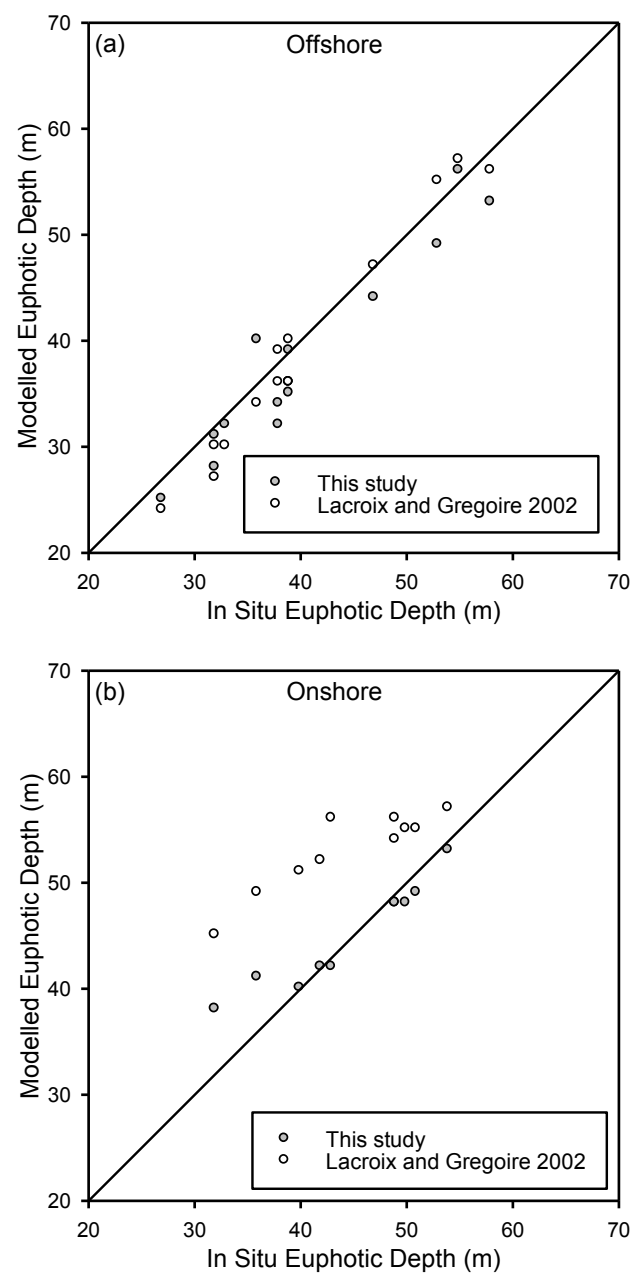

Figure 12. (a) Euphotic depth is modelled for offshore waters with similar accuracy by

540 the model presented here and the previous model by Lacroix and Gregoire (2002). (b) The

541 Lacroix and Gregoire (2002) model over-estimates euphotic depth for optically complex on

542 shore waters. The model presented here performs better in these waters as it captures the effect

543 of non-algal materials as well as phytoplankton.

544 The Ligurian Sea bio-optical model developed here has been specifically designed to

545 be able to accommodate a wide variety of potential data sources and to integrate into ecosystem

546 models with minimal need for adaptation. Generating estimates of Chl, TSS and Salinity from

547 in situ data is reasonably straightforward, though there is obviously scope for complications

548 under some circumstances e.g. strong differences in fluorescence: $C h l$ can occur under light,

549 nutrient or species composition gradients. Nonetheless, the performance of the model across 
550 the wide range of conditions encountered in this data set suggests that such effects may not be 551 fatal to performance under reasonably common circumstances.

OCRS is a potentially important data source for assimilation and validation of coupled

553 physical-ecosystem models, with optical closure against measured reflectance data, such as is

554 demonstrated here, being a useful tool for tracking model performance. Chang et al. (2006)

555 have shown how it might be possible to use reflectance spectra for further refinement of water 556 masses. However, caution is required in the interpretation of OCRS standard products in 557 optically complex waters. An example of where due caution is required is illustrated in Figure

558 1. Standard OCRS Chl products based on blue-green reflectance ratios tend to perform poorly 559 in turbid coastal waters (e.g. McKee et al. 2007), with high sediment levels resulting in the 560 return of over-estimates of $C h l$. This is most likely the case with the Arno plume seen in the 561 centre of Figures 1 (c and d). It would be essential to establish the performance of OCRS 562 algorithms in the region of interest before using such data to estimate $C h l$ and TSS. Obtaining 563 Salinity from space is even more challenging, with sensors such as the now-defunct Aquarius 564 offering much lower resolution than would be required to resolve important features such as 565 the Arno plume that features strongly in this area. Direct estimation of CDOM absorption from 566 ocean colour remote sensing, if available, would provide a welcome alternative data source for

567 this kind of application. Whilst ocean colour CDOM products are available, it is not clear that 568 they are able to achieve the level of discrimination between dissolved CDOM and detrital 569 particulate absorption that is necessary for this application. This is an area that requires further 570 development at this time. On the modeling side, both $C h l$ and Salinity are commonly used 571 model currencies that fit seamlessly with the bio-optical model for the Ligurian Sea. However, 572 the non-biogenic TSS component requires inclusion of benthic resuspension and lateral 573 transport of mineral particles to be included in the coupled physical-ecosystem model (Everett 574 et al. 2007, Sheng and Kim 2009). This feature is not included by default in many such models 
575 and introduction of these processes would potentially impact on computation time and would 576 require specific validation. However, given the influence on euphotic depth and light 577 availability for photosynthesis, and the impact on remote sensing reflectance signals that are 578 often proposed for model assimilation and validation schemes, it seems clear that modeling 579 mineral particle transport and dispersal is a necessary step for shallow coastal waters. This 580 work strongly points towards this being an important area for coastal and shelf sea model 581 development.

The next logical step in this work is to attempt to incorporate a radiative transfer model using the bio-optical relationships established here into a coupled physical-ecosystem model

584 for the Ligurian Sea and compare performance with and without (a) any light field model, (b)

585 a Case 1 only bio-optical model, and (c) the integrated Case 1 and Case 2 bio-optical model 586 (Mobley et al. 2015). As well as directly impacting on phytoplankton productivity estimates, 587 there is scope to influence solar heating of the water column with potential impacts on 588 stratification and possibly circulation in some cases (Murtugudde et al. 2002). Further efforts 589 along this line of research are planned.

\section{Acknowledgements}

593 visiting researcher program (Bengil), British Council travel grant (Bengil) and award of a 594 NERC Advanced Fellowship (NE/E013678/1 - McKee). We would like to thank the captain 595 and crew of $N R / V$ Alliance for their assistance during data collection at sea. We would also like 596 to thank collaborators from the BP09 cruise who kindly provided access to ancillary data sets. 597 Comments from Grace Chang and two anonymous reviewers were very gratefully received. 


\section{References}

600 Astraldi, M., Gasparini, G.P., 1992. The Seasonal Characteristics of the Circulation in the 601 North Mediterranean Basin and Their Relationship with the Atmospheric-Climatic Conditions. J. Earth Syst. Sci. 97, 9531-9540.

Astraldi, M., Gasparini, G.P., Manzella, G.M.R., Hopkins, T.S., 1990. Temporal Variability of 604 Currents in the Eastern Ligurian Sea. J. Geophys. Res. 95, 1515-1522.

605

Babin, Marcel; Stramski Dariusz, Ferrari M. Giovanni, Claustre Herve, Bricaud Annick, 606 Obolensky Grigor, H.N., Babin, M., Stramski, D., Ferrari, G.M., Claustre, H., Bricaud, A., Obolensky, G., Hoepffner, N., 2003. Variations in the light absorption coefficients of phytoplankton, nonalgal particles, and dissolved organic matter in coastal waters around

Beşiktepe, Ş., T., Lermusiaux, P.F.J., Robinson, A.R., 2003. Coupled physical and biogeochemical data-driven simulations of Massachusetts Bay in late summer: Real-time and postcruise data assimilation. J. Mar. Syst. 40-41, 171-212. doi:10.1016/S09247963(03)00018-6

614 Bowers, D.G., Harker, G.E.L., Smith, P.S.D., Tett, P., 2000. Optical properties of a region of 615 freshwater influence (The Clyde Sea). Estuar. Coast. Shelf Sci. 50, 717-726.

Bricaud, A., Morel, A., Babin, M., Allali, K., Claustre, H., 1998. Variations of light absorption by suspended particles with chlorophyll a concentration in oceanic (case 1) waters: Analysis and implications of r bio-optical models. J. Geophys. Res. 103, 31033-31044.

619 Bricaud, A., Roesler, C., Zaneveld, J.R. V., 1995. In situ methods for measuring the inherent 620 optical properties of ocean waters. Limnol. Oceanogr. 40, 393-410. doi:10.4319/1o.1995.40.2.0393 
622 Chang, G.C., Barnard, A. H., McLean, S., Egli, P.J., Moore, C., Zaneveld, J.R.V., Dickey, T.D., 623 Hanson, A., 2006. In situ optical variability and relationships in the Santa Barbara 624 Channel: implications for remote sensing, Appl. Opt., 45, 3593-3604.

625 Ciavatta, S., Torres, R., Martinez-Vicente, V., Smyth, T., Olmo, G.D., Polimene, L., Allen, J. 626 I., 2014. Assimilation of remotely-sensed optical properties to improve marine 627 biogeochemistry modelling. Prog. Oceanogr. 127, 74-95.

628 Cleveland, J.S., Weidemann, A.D., 1993. Quantifying absorption by aquatic particles: A 629 multiple scattering correction for glass-fiber filters. Limnol. Oceanogr. 38, 1321-1327. $630 \quad$ doi:10.4319/10.1993.38.6.1321

631 Dickey, T., Lewis, M., Chang, G., 2006. Optical oceanography: recent advances and future 632 directions using global remote sensing and in situ observations. Rev. Geophys. 44, 1-39. 633 doi:10.1029/2003RG000148.1

634 Dickey, T.D., Falkowski, P.G., 2002. Solar energy and its biological - physical interactions in 635 the sea, The Sea. John Wiley \& Sons, Inc., New York.

636 Doerffer, R., Schiller, H., 2007. Measurements of optical absorption by chromophoric 637 dissolved organic matter using a point-source integrating-cavity absorption meter. Int. J. $638 \quad$ Remote Sens. 28, 517-535.

639 Everett, J.D., Baird, M.E., Suthers, I.M., 2007. Nutrient and plankton dynamics in an 640 intermittently closed/open lagoon, Smiths Lake, south-eastern Australia: An ecological 641 model. Estuar. Coast. Shelf Sci. 72, 690-702. doi:10.1016/j.ecss.2006.12.001

642 Fujii, M., Boss, E., Chai, F., 2007. The value of adding optics to ecosystem models : a case $643 \quad$ study. Biogeoscience 4, 817-835.

644 Gordon, H.R., Morel, A., 1981. Water Colour Measurements - An Introduction. Mar. Sci. 13, $645 \quad 207-212$. 
646 Klemas, V., Borchardt, J.F., Treasure, W.M., 1973. Suspended sediments observations from ERTS-1. Remote Sens. Environ. 2, 205-221.

648 Lacroix, G., Gregoire, M., 2002. Revisited ecosystem model (MODECOGeL) of the Ligurian 649 Sea: seasonal and interannual variability due to atmospheric forcing. J. Mar. Syst. 37, 650 229-258. doi:http://dx.doi.org/10.1016/S0924-7963(02)00190-2

651 Lacroix, G., Nival, P., 1998. Influence of meteorological variability on primary production 652 dynamics in the Ligurian Sea (NW Mediterranean Sea) with a 1D hydrodynamic/biological model. J. Mar. Syst. 16, 23-50. doi:10.1016/S09247963(97)00098-5

Lee, Z.P., Du, K.P., Arnone, R., Liew, S.C., Penta, B., 2005. Penetration of solar radiation in the upper ocean: A numerical model for oceanic and coastal waters. Journal of Geophysical Research C: Oceans, 110 (9), art. no. C09019, pp. 1-12. doi:10.1029/2004JC002780

Lefering, I., Bengil, F., Trees, C., Röttgers, R., Bowers, D., Nimmo-Smith, W.A.M, Schwarz, J., McKee, D. 2016. Optical closure in marine waters from in situ inherent optical property measurements. Opt. Expr. 24, 14036-14052.

Loisel, H., Morel, A., 1998. Light scattering and chlorophyll concentration in case 1 waters: A reexamination. Limnol. Oceanogr. 43, 847-858. doi:10.4319/1o.1998.43.5.0847

664 Marty, J.C., Chiavérini, J., Pizay, M.D., Avril, B., 2002. Seasonal and interannual dynamics of 665 1965-1985. doi:10.1016/S0967-0645(02)00022-X

McKee, D., Röttgers, R., Neukermans, G., Calzado, V.S., Trees, C., Ampolo-Rella, M., Neil, 669 C., Cunningham, A., 2014. Impact of measurement uncertainties on determination of 

Chlorophyll-specific absorption coefficient for marine phytoplankton. Geophys. Res. Ocean. 119, 9013-9025.

672 Mobley, C.D., Chai, F., Xiu, P., Sundman, L.K., 2015. Impact of improved light calculations 673 on predicted phytoplankton growth and heating in an idealized upwelling-downwelling 674 channel geometry. J. Geophys. Res. Ocean. 120, 875-892. doi:10.1002/2014JC010588

675 Mobley, C.D., Sundman, L.K., Boss, E., 2002. Phase function effects on oceanic light fields. 676 Appl. Opt. 41, 1035. doi:10.1364/AO.41.001035

677 Morel, A., Maritorena, S., 2001. Bio-optical properties of oceanic waters: A reappraisal. J. $678 \quad$ Geophys. Res. 106, 7163-7180.

679 Morel, A., 2009. Are the empirical relationships describing the bio-optical properties of case 1 680 waters consistent and internally compatible? J. Geophys. Res. Ocean. 114, 1-15. 681 doi:10.1029/2008JC004803

Morel, A., 1988. Optical Modeling of the Upper Ocean in Relation to Its Biogenous Matter 683 Content (Case I Waters). J. Geophys. Res. 93, C9, 10749 - 10768.

684 Murtugudde, R., Beauchamp, J., McClain, C.R., Lewis, M., Busalacchi, A.J., 2002. Effects of 685 penetrative radiation on the upper tropical ocean circulation. J. Clim. 15, 470-486.

Pegau, W., Gray, D., Zaneveld, J., 1997. Absorption and attenuation of visible and near687 infrared light in water: dependence on temperature and salinity. Appl. Opt. 36, 6035688 6046.

Penta, B., Lee, Z., Kudela, R.M., Palacios, S.L., Gray, D.J., Jolliff, J.K., Shulman, I.G., 2008. An underwater light attenuation scheme for marine ecosystem models. Opt. Expr. 16 (21), 16581-16591.

692 Penta, B., Lee, Z., Kudela, R.M., Palacios, S.L., Gray, D.J., Jolliff, J.K., Shulman, I.G., 2009. 693 An underwater light attenuation scheme for marine ecosystem models: errata. Opt. Expr. 694 $17(25), 23351$. 
695 Picco, P., Cappelletti, a., Sparnocchia, S., Schiano, M.E., Pensieri, S., Bozzano, R., 2010.

696 Upper layer current variability in the Central Ligurian Sea. Ocean Sci. 6, 825-836.

697 doi:10.5194/os-6-825-2010

698 Prieur, L., Sathyendranath, S., 1981. An Optical Classification of Coastal and Oceanic Waters 699 Based on the Specific Spectral Absorption Curves of Phytoplankton Pigments, Dissolved

Raick, C., Delhez, E.J.M., Soetaert, K., Grégoire, M., 2005. Study of the seasonal cycle of the 703 biogeochemical processes in the Ligurian Sea using a 1D interdisciplinary model. J. Mar. Syst. 55, 177-203. doi:10.1016/j.jmarsys.2004.09.005

705

Rothstein, L., Cullen, J., Abbott, M., Chassignet, E., Denman, K., Doney, S., Ducklow, H., 706 Fennel, K., Follows, M., Haidvogel, D., Hofmann, E., Karl, D., Kindle, J., Lima, I.,

Röttgers, R., Doerffer, R., 2007. Measurements of optical absorption by chromophoric Maltrud, M., McClain, C., McGillicuddy, D., Olascoaga, M.J., Spitz, Y., Wiggert, J., Yoder, J., 2006. Modeling Ocean Ecosystems: The PARADIGM Program. Oceanography dissolved organic matter using a point-source integrating-cavity absorption meter. Limnol. Oceanogr. Methods 5, 126-135.

Röttgers, R., Schönfeld, W., Kipp, P.-R., Doerffer, R., 2005. Practical test of a point-source integrating cavity absorption meter: the performance of different collector assemblies.

716 Röttgers, R., Häse, C., Doerffer, R., 2007. Determination of the particulate absorption of 717 microalgae using a point-source integrating-cavity absorption meter: verification with a 718 photometric technique, improvements for pigment bleaching, and correction for chlorophyll fluorescence. Limnol. Oceanogr. Methods 5, 1-12. doi:10.4319/lom.2007.5.1 
Sanjuan Calzado, V., 2009. Bio-optical modeling for ecosystems in case II waters. Univ. Southampton, Sch. Ocean Earth Sci.

Sheng, Y.P., Kim, T., 2009. Skill assessment of an integrated modeling system for shallow coastal and estuarine ecosystems. J. Mar. Syst. 76, 212-243. doi:10.1016/j.jmarsys.2008.05.011

Shulman, I., Frolov, S., Anderson, S., Penta, B., Gould, R., Sakalaukus, P., Ladner, S., 2013. Impact of bio-optical data assimilation on short-term coupled physical, bio-optical model predictions. J. Geophys. Res. Ocean. 118, 2215-2230. doi:10.1002/jgrc.20177

Trees, C., Sanjuan Calzado, V., Besiktepe, S., McKee, D., Bengil, F., Gunduz, M., Twardowski, M., 2012. Optical physical and ecosystem regional modeling Assessment (OPERA): A revolutionary Approach, in Ocean Optics XXI. Glasgow.

Tzortziou, M., Herman, J.R., Gallegos, C.L., Neale, P.J., Subramaniam, A., Harding, L.W., Ahmad, Z., 2006. Bio-optics of the Chesapeake Bay from measurements and radiative transfer closure. Estuar. Coast. Shelf Sci. 68, 348-362. doi:10.1016/j.ecss.2006.02.016

Vellucci, V., 2007. Optical properties in the Mediterranean open waters. PhD Thesis from Università Degli Studi Di Napoli “Federico II".

Werdell, P.J., Bailey, S.W., 2005. An improved in-situ bio-optical data set for ocean color algorithm development and satellite data product validation. Remote Sens. Environ. 98, $122-140$.

Zaneveld, J.R. V., Kitchen, J.C., Moore, C., 1994. The scattering Error Correction of Reflecting-Tube Absorption Meters. Ocean Opt. XII. Int. Soc. Opt. Photonics. doi:10.1117/12.190095

Zibordi, G., Berthon, J.F., Melin, F., D’Alimonte, D., 2011. Cross-site consistent in situ measurements for satellite ocean color applications: The BiOMaP radiometric dataset. Remote Sens. Environ. 15, 2104-2115. 